\title{
Características do pasto de capim-tanzânia adubado com nitrogênio no final do verão
}

\author{
Valéria Pacheco Batista Euclides ${ }^{(1)}$, Manuel Cláudio Motta Macedo(1), Ademir Hugo Zimmer ${ }^{(1)}$, \\ Rodrigo Narciso de Medeiros ${ }^{(1)}$ e Marcelo Paschoal de Oliveira ${ }^{(1)}$
}

\begin{abstract}
(1)Embrapa Gado de Corte, Rod. Br 262, Km 04, Caixa Postal 154, CEP $79002-970$ Campo Grande, MS. E-mail: val@cnpgc.embrapa.br, macedo@cnpgc.embrapa.br, zimmer@cnpgc.embrapa.br, r.medeiros@cnpgc.embrapa.br, marcelo@cnpgc.embrapa.br
\end{abstract}

\begin{abstract}
Resumo - O objetivo deste trabalho foi avaliar a massa de forragem, os componentes morfológicos e o valor nutritivo de Panicum maximum cultivar Tanzânia, com aplicação de uma segunda dose de adubação nitrogenada em março, no final do verão. Anualmente, foram aplicados em cobertura 50, 17,5 e 33,2 $\mathrm{kg} \mathrm{ha}^{-1}$ de N, P e K, respectivamente, em novembro. Além disso, a metade da área recebeu $50 \mathrm{~kg} \mathrm{ha}^{-1}$ de $\mathrm{N}$ adicional, em março. Os tratamentos foram doses de $50 \mathrm{e} 100 \mathrm{~kg} \mathrm{ha}^{-1} \mathrm{de} \mathrm{Nem}$ pastos de capim-tanzânia. Os piquetes foram subdivididos em seis e submetidos ao pastejo rotacionado. Foram avaliados a massa de forragem, os componentes morfológicos e o valor nutritivo. A aplicação adicional de $\mathrm{N}$, em março, promoveu aumento nas taxas de acúmulo de matéria seca verde e de lâmina foliares, com maiores efeitos no outono. Houve acréscimos nos teores de proteína bruta e de digestibilidade in vitro da matéria orgânica da forrageira logo após a aplicação do N. A adubação com $50 \mathrm{~kg} \mathrm{ha}^{-1}$ por ano de $\mathrm{N}$ foi suficiente para manter a produção de forragem estável durante três anos, sob pastejo. A aplicação de $50 \mathrm{~kg} \mathrm{ha}^{-1}$ por ano de $\mathrm{N}$ adicional, em março, diminuiu a estacionalidade da produção forrageira, além de produzir forragem de maior valor nutritivo durante o outono.
\end{abstract}

Termos para indexação: Panicum maximum, produção de forragem, Latossolo, componentes morfológicos, manejo de pastagem, valor nutritivo.

\section{Pasture characteristics of Panicum maximum cv. Tanzânia fertilized with nitrogen in the end of summer}

\begin{abstract}
The objective of this work was to evaluate the forage yield, morphological components and nutritive value of Panicum maximum cv. Tanzânia, with a second application of nitrogen fertilizer in March, at the end of summer. Maintenance fertilizer was 50, 17.5 and $33.2 \mathrm{~kg} \mathrm{ha}^{-1}$ of N, P and K, respectively, applied annually, in November. Besides, in half of the area, an additional $50 \mathrm{~kg} \mathrm{ha}^{-1}$ of $\mathrm{N}$ was applied, in March. The treatments were tanzânia pasture with two levels of nitrogen fertilization, 50 and $100 \mathrm{~kg} \mathrm{ha}^{-1}$. The paddocks were divided in six plots, and submitted to a rotational grazing. Forage yield, percentages of the morphological components and nutritive value were evaluated. The accumulation rates of green dry matter and leaf dry matter, mainly in autumn, were greater for pastures that received $50 \mathrm{~kg} \mathrm{ha}^{-1}$ of $\mathrm{N}$ additional in March. There were increases in the percentages of crude protein and in vitro organic matter digestibility, before and after grazing, after nitrogen application. The fertilization with $50 \mathrm{~kg} \mathrm{ha}^{-1}$ per year of $\mathrm{N}$ was enough to keep forage yield stable during three years under grazing. The fertilization with additional $50 \mathrm{~kg} \mathrm{ha}^{-1}$ per year of $\mathrm{N}$, in March, decreased seasonal dependence of forage production, besides yielding forage with a higher nutritive value during autumn.
\end{abstract}

Index terms: Panicum maximum, forage yield, Oxisol, morphological components, pasture management, nutritive value.

\section{Introdução}

Estudos realizados em solos da Região do Cerrado têm demonstrado que a saturação por bases trocáveis e os conteúdos de fósforo são fatores diretamente relacionados à produtividade das pastagens e à sua sustentabilidade (Macedo, 1997). Uma vez feitas essas correções, a produção é altamente dependente da adubação nitrogenada (Macedo, 1995).

Embora o uso de adubos nitrogenados seja uma maneira efetiva de repor $\mathrm{N}$ no sistema de produção, sua adoção pelos pecuaristas ainda é limitada; entre outras 
razões, Martha Junior et al. (2004) atribuíram isto ao fato de o pecuarista não aplicar fertilizante em pastagens e à incerteza quanto ao desempenho bioeconômico da adubação nitrogenada de pastagens, em razão da variabilidade encontrada nas respostas do pasto e do animal a esse insumo.

Além disso, a fonte potencial e natural de $\mathrm{N}$ para a sustentabilidade da produção está no $\mathrm{N}$ derivado da ciclagem no complexo solo-planta-animal. Teores de matéria orgânica (MO) em solos sob pastagens aumentam com o tempo, e isto indica que o grande reservatório de $\mathrm{N}$ está no complexo orgânico sob o solo. Entretanto, segundo Macedo (1995), o que se observa com o tempo é a insuficiência de $\mathrm{N}$ disponível para manter a produtividade em pastagens de gramíneas, mesmo com o aumento do teor de MO do solo. Cadish et al. (1994) estimaram que o deficit anual de N, em gramíneas tropicais cultivadas em solos de cerrado, é de 60 a $100 \mathrm{~kg} \mathrm{ha}^{-1}$. Portanto, para manter a sustentabilidade da produção, alguma adubação nitrogenada de manutenção se faz necessária. Deve-se considerar, no entanto, o aspecto econômico da adubação nitrogenada. Werner et al. (1996) propuseram adubações de manutenção de 40 a $80 \mathrm{~kg} \mathrm{ha}^{-1}$ de $\mathrm{N}$ a depender do grau de exigência da planta forrageira.

Sabe-se que as forrageiras não crescem uniformemente ao longo do ano (Euclides, 2000; Brâncio et al., 2003; Barbosa et al., 2007). Além de variações de temperatura e fotoperíodo, a estacionalidade das chuvas, característica das regiões tropicais, não permite produção uniforme de forragem durante o ano (Penati, 2002; Barbosa et al., 2007).
Essa estacionalidade na produção de forragem gera a estacionalidade na produção animal em pasto. Assim, em sistemas com uso moderado de insumos, o uso estratégico do $\mathrm{N}$ fertilizante pode aumentar a produção de forragem no outono, para ser utilizada na época seca. Werner (1971) comparou épocas de aplicação de $\mathrm{N}$ em pastos de capim-colonião, com o objetivo de determinar épocas de aplicação da adubação nitrogenada, para amenizar a deficiência de forragem no período crítico. $\mathrm{O}$ autor concluiu que a metade ou $1 / 3$ da dose total de $\mathrm{N}$ deve ser aplicada em dezembro ou janeiro e o restante em março, para diminuir a sazonalidade da produção forrageira.

O objetivo deste trabalho foi avaliar a massa de forragem, os componentes morfológicos e o valor nutritivo de pastos de Panicum maximum cultivar Tanzânia, com e sem a aplicação de $\mathrm{N}$ no final do verão.

\section{Material e Métodos}

Este experimento foi conduzido na Embrapa Gado de Corte (CNPGC), em Campo Grande, MS, de novembro de 1993 a abril de 1999. O padrão climático da região, segundo Köppen, é o pertencente à faixa de transição entre $\mathrm{Cfa}$ e Aw tropical úmido. A precipitação média anual é de $1.560 \mathrm{~mm}$, e o período considerado de seca vai de maio a setembro (30\% da precipitação anual). $\mathrm{O}$ balanço hídrico do período experimental encontra-se na Figura 1.

O solo da área experimental é classificado como Latossolo Vermelho distrófico (Embrapa, 1999). Após a

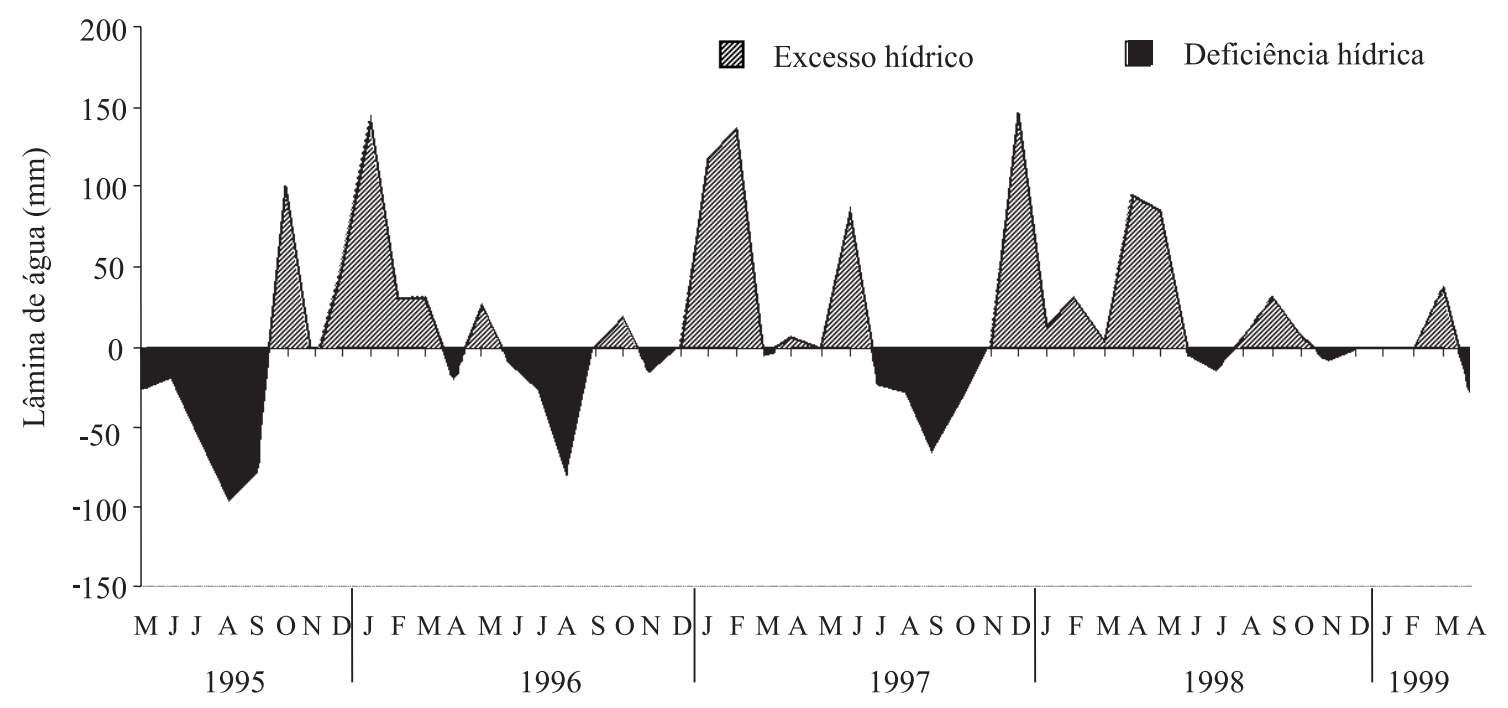

Figura 1. Balanço hídrico mensal, de maio de 1995 a abril de 1999. 
derrubada da vegetação e preparo do solo, foram feitas correção e adubação que consistiram de $3,7 \mathrm{tha}^{-1}$ de

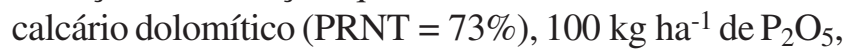
$75 \mathrm{~kg} \mathrm{ha}^{-1}$ de $\mathrm{K}_{2} \mathrm{O}$ e $50 \mathrm{~kg} \mathrm{ha}^{-1}$ de FTE BR-12. Foram semeados $2 \mathrm{~kg} \mathrm{ha}^{-1}$ de sementes puras viáveis de capimtanzânia (Panicum maximum cultivar Tanzânia). Após a cobertura das sementes com uma gradagem leve, foi feita a compactação do solo com um rolo compactador constituído de pneus.

Anualmente, foram aplicados em cobertura: em outubro, $40 \mathrm{~kg} \mathrm{ha}^{-1}$ de $\mathrm{P}_{2} \mathrm{O}_{5}$ e de $\mathrm{K}_{2} \mathrm{O}$; e em novembro, $50 \mathrm{~kg} \mathrm{ha}^{-1}$ de $\mathrm{N}$, na forma de uréia e de sulfato de amônio, em anos alternados. Em setembro de 1995 e 1997, foram aplicados em cobertura 1,2 e $2 \mathrm{t} \mathrm{ha}^{-1}$ de calcário dolomítico $(\mathrm{PRNT}=80 \%)$, respectivamente, com o objetivo de manter a saturação por bases do solo em pelo menos $40 \%$. A metade da área, recebeu $50 \mathrm{~kg} \mathrm{ha}^{-1}$ de $\mathrm{N}$ adicional, em março, na forma de uréia e de sulfato de amônio, em anos alternados.

O delineamento experimental foi o de blocos ao acaso, com dois tratamentos e duas repetições. Os tratamentos foram pastos de capim-tanzânia, com adubação nitrogenada de $50 \mathrm{~kg} \mathrm{ha}^{-1}$ de $\mathrm{N}$ e de $100 \mathrm{~kg}$ de $\mathrm{N}$.

Os pastos foram implantados em fevereiro de 1994, mas em razão de problemas operacionais, só foi possível iniciar o experimento em maio de 1995.

Os piquetes de 1,5 ha foram subdivididos em seis, manejados sob lotação intermitente com sete dias de utilização e 35 dias de descanso. Cada piquete foi pastejado por quatro novilhos (animais avaliadores) distribuídos ao acaso. Animais reguladores, da mesma categoria, foram colocados e removidos de cada piquete de acordo com a disponibilidade de forragem, o que assegurou, entre os tratamentos, resíduos pós-pastejo em torno de 2,5 $\mathrm{t} \mathrm{ha}^{-1}$ de matéria seca. Anualmente, em maio, os animais foram substituídos por outros animais da mesma categoria.

Os pastos foram amostrados no pré e no póspastejo. Para se estimar a massa de forragem, foram cortadas, ao acaso, em cada piquete, a $15 \mathrm{~cm}$ do solo, 24 amostras de $1 \mathrm{~m}^{2}$, as quais foram divididas em duas subamostras: uma foi secada e pesada, e a outra foi separada em lâmina foliar (LF), colmo (bainha e colmo; Co) e material morto (MM). A proporção de cada componente morfológico foi expressada como porcentagem do peso total. Adicionalmente, em cada piquete no pré e no pós-pastejo, foram coletadas duas amostras para simulação do pastejo animal para se estimar o valor nutritivo.

Para avaliação dos teores de proteína bruta (PB), fibra em detergente neutro (FDN), lignina em detergente ácido (LDA) e digestibilidade in vitro da matéria orgânica (DIVMO), utilizou-se a espectroscopia de reflectância do infravermelho próximo (NIRS), conforme Marten et al. (1985). Os dados de reflectância das amostras, na faixa de comprimentos de onda de 1.100 a $2.500 \mathrm{~mm}$, foram armazenados por um espectrômetro modelo NR5000 acoplado a um microcomputador.

Os dados foram agrupados por épocas do ano, de maio a setembro (período seco) e de outubro a abril (período das águas), e analisados por um modelo matemático com os efeitos fixos de tratamento, bloco, período do ano, ano de avaliação, e as interações entre esses.

Todas as análises foram feitas pelo método dos quadrados mínimos pelo procedimento General Linear Model (SAS Institute, 1996). Os comandos random e test foram utilizados para a identificação e realização dos testes apropriados para cada variável independente. A comparação de médias foi realizada pelo teste de Tukey, a 5\% de probabilidade; e no caso de interações significativas, a comparação de média foi realizada por meio de contrastes, tendo-se adotado 5\% de probabilidade.

Para os acúmulos de matéria seca verde e de lâmina foliar, o mês foi analisado como variável contínua. Com base em análises prévias, selecionou-se o polinomial de maior ordem para cada variável dependente.

\section{Resultados e Discussão}

As massas de matéria seca (MST) e de matéria seca verde (MSV), e as porcentagens de lâminas foliares (PLF) e de colmo (PCo), antes do pastejo, foram semelhantes $(p>0,10)$ para os pastos adubados com 50 e $100 \mathrm{~kg} \mathrm{ha}^{-1}$ de N. No entanto, elas foram diferentes $(\mathrm{p}<0,05)$ entre as estações do ano e entre anos experimentais. Também foi observada interação $(\mathrm{p}<0,05)$ entre a adubação nitrogenada, período do ano e ano experimental (Tabelas 1 e 2).

No período das águas, o pasto adubado com $100 \mathrm{~kg} \mathrm{ha}^{-1}$ de N (N100) apresentou maior valor de massa de MST do que aquele adubado com $50 \mathrm{~kg} \mathrm{ha}^{-1}$ de N (N50) só no quarto ano experimental (1998/1999). Esse comportamento provavelmente foi conseqüência dos efeitos residuais da adubação da dose N100, pois a dose N50 não foi suficiente para sustentar a produção 
Tabela 1. Médias dos quadrados mínimos para as massas de matéria seca total (MST) e de matéria seca verde (MSV), no prépastejo dos pastos de Panicum maximum cultivar Tanzânia, com duas doses de adubação nitrogenada (N50 e N100), de acordo com o ano e o período do ano ${ }^{(1)}$.

\begin{tabular}{|c|c|c|c|c|c|c|}
\hline \multirow[t]{2}{*}{ Ano } & \multicolumn{3}{|c|}{ Período das águas } & \multicolumn{3}{|c|}{ Período seco } \\
\hline & N50 & N100 & Média & N50 & N100 & Média \\
\hline & \multicolumn{6}{|c|}{$\operatorname{MST}\left(\mathrm{kg} \mathrm{ha}^{-1}\right)$} \\
\hline $1995 / 1996$ & $\begin{array}{c}3.380 \mathrm{Aa} \\
(109)\end{array}$ & $\begin{array}{c}\text { 3.630Aa } \\
(109)\end{array}$ & $\begin{array}{l}3.505 \\
(113)\end{array}$ & $\begin{array}{c}2.745 \mathrm{Ba} \\
(99)\end{array}$ & $\begin{array}{c}3.265 \mathrm{Aa} \\
(99)\end{array}$ & $\begin{array}{l}3.005 \\
(103)\end{array}$ \\
\hline $1996 / 1997$ & $\begin{array}{c}\text { 3.000ABa } \\
\text { (77) }\end{array}$ & $\begin{array}{c}3.265 \mathrm{Aa} \\
(78)\end{array}$ & $\begin{array}{c}3.135 \\
(80)\end{array}$ & $\begin{array}{c}2.805 \mathrm{Ba} \\
(109)\end{array}$ & $\begin{array}{c}2.855 \mathrm{ABa} \\
(109)\end{array}$ & $\begin{array}{l}2.830 \\
(113)\end{array}$ \\
\hline 1997/1998 & $\begin{array}{c}3.195 \mathrm{Aa} \\
(89)\end{array}$ & $\begin{array}{c}3.385 \mathrm{Aa} \\
(89)\end{array}$ & $\begin{array}{c}3.290 \\
(92)\end{array}$ & $\begin{array}{c}2.205 \mathrm{Ba} \\
(73)\end{array}$ & $\begin{array}{c}2.435 \mathrm{Ba} \\
(73)\end{array}$ & $\begin{array}{c}2.320 \\
(76)\end{array}$ \\
\hline 1998/1999 & $\begin{array}{c}2.740 \mathrm{Bb} \\
(92)\end{array}$ & $\begin{array}{c}3.265 \mathrm{Aa} \\
(89)\end{array}$ & $\begin{array}{c}3.000 \\
(94)\end{array}$ & $\begin{array}{c}3.640 \mathrm{Aa} \\
(125)\end{array}$ & $\begin{array}{c}3.325 \mathrm{Aa} \\
(125)\end{array}$ & $\begin{array}{l}3.480 \\
(130)\end{array}$ \\
\hline Média & $\begin{array}{c}3.080 \\
(70)\end{array}$ & $\begin{array}{l}3.385 \\
(70)\end{array}$ & & $\begin{array}{l}2.845 \\
(78)\end{array}$ & $\begin{array}{c}2.970 \\
(78)\end{array}$ & \\
\hline & \multicolumn{6}{|c|}{$\operatorname{MSV}\left(\mathrm{kg} \mathrm{ha}^{-1}\right)$} \\
\hline $1995 / 1996$ & $\begin{array}{c}2.640 \mathrm{Aa} \\
(76)\end{array}$ & $\begin{array}{c}2.825 \mathrm{Aa} \\
(76)\end{array}$ & $\begin{array}{c}2.735 \\
(68)\end{array}$ & $\begin{array}{c}1.310 \mathrm{Bb} \\
(69)\end{array}$ & $\begin{array}{c}1.660 \mathrm{Ba} \\
(69)\end{array}$ & $\begin{array}{c}1.460 \\
(62)\end{array}$ \\
\hline 1996/1997 & $\begin{array}{c}2.375 \mathrm{Ba} \\
(53)\end{array}$ & $\begin{array}{c}2.630 \mathrm{Aa} \\
(53)\end{array}$ & $\begin{array}{c}2.500 \\
(48)\end{array}$ & $\begin{array}{c}1.150 \mathrm{Ba} \\
(76)\end{array}$ & $\begin{array}{c}1.240 \mathrm{Ba} \\
(76)\end{array}$ & $\begin{array}{c}1.195 \\
(68)\end{array}$ \\
\hline $1997 / 1998$ & $\begin{array}{c}2.715 \mathrm{Aa} \\
(62)\end{array}$ & $\begin{array}{c}2.905 \mathrm{Aa} \\
(62)\end{array}$ & $\begin{array}{c}2.810 \\
(55)\end{array}$ & $\begin{array}{c}1.050 \mathrm{Bb} \\
(51)\end{array}$ & $\begin{array}{c}1.415 \mathrm{Ba} \\
(51)\end{array}$ & $\begin{array}{c}1.230 \\
(46)\end{array}$ \\
\hline 1998/1999 & $\begin{array}{c}2.405 \mathrm{ABa} \\
(64)\end{array}$ & $\begin{array}{c}2.690 \mathrm{Aa} \\
(62)\end{array}$ & $\begin{array}{c}2.550 \\
(56)\end{array}$ & $\begin{array}{c}2.015 \mathrm{Aa} \\
(87)\end{array}$ & $\begin{array}{c}2.235 \mathrm{Aa} \\
(87)\end{array}$ & $\begin{array}{c}2.125 \\
(78)\end{array}$ \\
\hline Média & $\begin{array}{c}2.535 \\
(55)\end{array}$ & $\begin{array}{c}2.765 \\
(55)\end{array}$ & & $\begin{array}{c}1.380 \\
(62)\end{array}$ & $\begin{array}{c}1.625 \\
(62)\end{array}$ & \\
\hline
\end{tabular}

(1)Médias seguidas de letras iguais, maiúsculas nas colunas e minúsculas nas linhas, dentro de cada período do ano, não diferem entre si pelo teste de Tukey, a 5\% de probabilidade; valores entre parênteses se referem ao erro-padrão da média.

Tabela 2. Médias dos quadrados mínimos para as porcentagens de lâminas foliares e de colmos no pré-pastejo dos pastos de Panicum maximum cultivar Tanzânia, com duas doses de N (N50 e N100), de acordo com o ano e o período do ano.

\begin{tabular}{|c|c|c|c|c|c|c|}
\hline \multirow[t]{2}{*}{$\overline{A n o}$} & \multicolumn{3}{|c|}{ Período das águas } & \multicolumn{3}{|c|}{ Período seco } \\
\hline & N50 & N100 & Média & N50 & N100 & Média \\
\hline & \multicolumn{6}{|c|}{ Lâminas foliares (\%) } \\
\hline $1995 / 1996$ & $\begin{array}{c}62,4 \mathrm{Ba} \\
(1,17)\end{array}$ & $\begin{array}{c}61,0 \mathrm{Ba} \\
(1,17)\end{array}$ & $\begin{array}{c}61,9 \\
(0,84)\end{array}$ & $\begin{array}{c}27,2 \mathrm{ABa} \\
(1,07)\end{array}$ & $\begin{array}{c}27,7 \mathrm{Ba} \\
(1,07)\end{array}$ & $\begin{array}{c}27,4 \\
(0,76)\end{array}$ \\
\hline 1996/1997 & $\begin{array}{c}63,4 \mathrm{Ba} \\
(0,83)\end{array}$ & $\begin{array}{l}65,8 \mathrm{ABa} \\
(0,83)\end{array}$ & $\begin{array}{c}64,7 \\
(0,59)\end{array}$ & $\begin{array}{c}22,1 \mathrm{Ba} \\
(1,17)\end{array}$ & $\begin{array}{c}26,6 \mathrm{Ba} \\
(1,17)\end{array}$ & $\begin{array}{c}24,3 \\
(0,84)\end{array}$ \\
\hline $1997 / 1998$ & $\begin{array}{l}68,2 \mathrm{ABa} \\
(0,96)\end{array}$ & $\begin{array}{c}71,7 \mathrm{Aa} \\
(0,96)\end{array}$ & $\begin{array}{c}70,0 \\
(0,68)\end{array}$ & $\begin{array}{c}31,3 \mathrm{Aa} \\
(0,79)\end{array}$ & $\begin{array}{c}35,9 \mathrm{Aa} \\
(0,79)\end{array}$ & $\begin{array}{c}33,6 \\
(0,56)\end{array}$ \\
\hline $1998 / 1999$ & $\begin{array}{c}71,2 \mathrm{Aa} \\
(0,99)\end{array}$ & $\begin{array}{l}63,7 \mathrm{ABb} \\
(0,96)\end{array}$ & $\begin{array}{c}67,5 \\
(0,70)\end{array}$ & $\begin{array}{c}33,9 \text { Aa } \\
(1,36)\end{array}$ & $\begin{array}{c}38,9 \text { Aa } \\
(1,36)\end{array}$ & $\begin{array}{c}36,4 \\
(0,97)\end{array}$ \\
\hline \multirow[t]{2}{*}{ Média } & $\begin{array}{c}66,3 \\
(0,98)\end{array}$ & $\begin{array}{c}65,6 \\
(0,97)\end{array}$ & & $\begin{array}{c}28,6 \\
(1,09)\end{array}$ & $\begin{array}{c}32,3 \\
(1,09)\end{array}$ & \\
\hline & \multicolumn{6}{|c|}{ Colmos (\%) } \\
\hline 1995/1996 & $\begin{array}{c}15,4 \mathrm{Aa} \\
(1,11)\end{array}$ & $\begin{array}{c}16,5 \mathrm{Aa} \\
(1,11)\end{array}$ & $\begin{array}{c}15,9 \\
(0,88)\end{array}$ & $\begin{array}{c}20,8 \mathrm{Aa} \\
(1,01)\end{array}$ & $\begin{array}{l}21,2 \mathrm{ABa} \\
(1,01)\end{array}$ & $\begin{array}{c}21,0 \\
(0,80)\end{array}$ \\
\hline $1996 / 1997$ & $\begin{array}{l}14,3 \mathrm{ABa} \\
(0,78)\end{array}$ & $\begin{array}{c}14,4 \mathrm{Aa} \\
(0,78)\end{array}$ & $\begin{array}{c}14,4 \\
(0,62)\end{array}$ & $\begin{array}{c}20,5 \mathrm{Aa} \\
(1,11)\end{array}$ & $\begin{array}{c}18,6 \mathrm{Ba} \\
(1,11)\end{array}$ & $\begin{array}{c}19,5 \\
(0,88)\end{array}$ \\
\hline 1997/1998 & $\begin{array}{c}15,8 \mathrm{Aa} \\
(0,90)\end{array}$ & $\begin{array}{c}14,4 \mathrm{Aa} \\
(0,90)\end{array}$ & $\begin{array}{c}15,1 \\
(0,72)\end{array}$ & $\begin{array}{c}14,3 \mathrm{Bb} \\
(0,75)\end{array}$ & $\begin{array}{l}20,1 \mathrm{ABa} \\
(0,75)\end{array}$ & $\begin{array}{c}17,2 \\
(0,59)\end{array}$ \\
\hline 1998/1999 & $\begin{array}{l}16,1 \mathrm{Aa} \\
(0,93)\end{array}$ & $\begin{array}{c}18,4 \mathrm{Aa} \\
(0,90)\end{array}$ & $\begin{array}{c}17,3 \\
(0,72)\end{array}$ & $\begin{array}{c}23,1 \mathrm{Aa} \\
(1,28)\end{array}$ & $\begin{array}{c}27,9 \mathrm{Aa} \\
(1,28)\end{array}$ & $\begin{array}{c}25,5 \\
(1,01)\end{array}$ \\
\hline Média & $\begin{array}{c}15,9 \\
(0,51)\end{array}$ & $\begin{array}{c}15,4 \\
(0,51)\end{array}$ & & $\begin{array}{c}22,0 \\
(0,57)\end{array}$ & $\begin{array}{c}19,7 \\
(0,57)\end{array}$ & \\
\hline
\end{tabular}

(1)Médias seguidas de letras iguais, maiúsculas nas colunas e minúsculas nas linhas, dentro de cada período do ano, não diferem entre si pelo teste de Tukey, a 5\% de probabilidade; valores entre parênteses se referem ao erro-padrão da média. 
de MST, a partir do terceiro ano de utilização do pasto. A menor produção de MST, e conseqüentemente da MSV, no pasto que recebeu apenas $50 \mathrm{~kg} \mathrm{ha}^{-1} \mathrm{de} \mathrm{N}$, no segundo e quarto ciclos de pastejo, provavelmente foi consequiência da interação entre a menor dose de adubação e a pior distribuição da precipitação pluviométrica, registradas nesses anos (Figura1). Ademais, as maiores variações na massa de forragem (Tabela 1) e na estrutura do pasto (Tabela 2) no prépastejo foram aquelas observadas entre os períodos das águas e da seca. Isto foi conseqüência da estacionalidade da produção da planta forrageira, comum em regiões tropicais, causada principalmente por deficit hídrico. E isto pode ser confirmado, quando se analisa a variação no acúmulo de lâminas foliares (LF), ao longo do ano (Figura 2).

Para ambos os tratamentos, a curva que melhor descreveu as taxas de acúmulo de LF foi a cúbica $(p<0,01)$. Foram observadas diferenças $(p<0,05)$ entre tratamentos, entretanto, não houve interação $(p>0,10)$ entre os efeitos de adubação e ano experimental, assim, esse acúmulo foi apresentado por tratamento em função dos meses (Figura 2). Independentemente da dose de adubação nitrogenada, maiores acúmulos de forragem foram observados nos meses de verão, intermediários nos meses de primavera e outono, e muito baixos nos meses de inverno (Figura 3). Esse padrão de variação também foi observado por Barbosa et al. (2007), para o acúmulo líquido de lâminas foliares em pastos de capimtanzânia adubados com $150 \mathrm{~kg} \mathrm{ha}^{-1} \mathrm{de} \mathrm{N}$, nesse mesmo local, no ano de 2003.

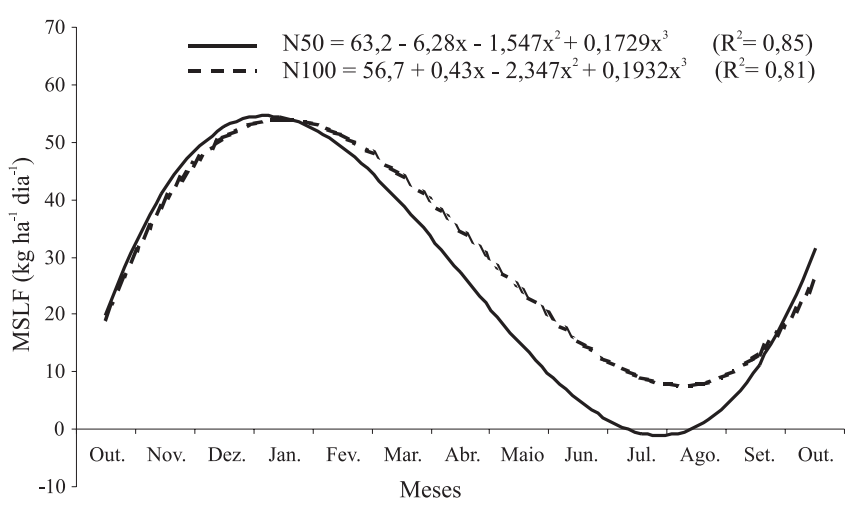

Figura 2. Taxa de acúmulo de matéria seca de lâminas foliares (MSLF) de pastos de Panicum maximum cultivar Tanzânia, com duas doses de N (N50 e N100), ao longo do ano.
Pode-se ainda ressaltar que os acréscimos nas taxas de acúmulo de LF, principalmente no outono-inverno, foram maiores $(\mathrm{p}<0,05)$ para o pasto adubado com $50 \mathrm{~kg} \mathrm{ha}^{-1}$ de $\mathrm{N}$ adicional, em março (Figura 2), o que resultou em maiores massas de MSV para serem utilizadas durante o período seco (Tabela 1), nos pastos adubados com $50 \mathrm{~kg} \mathrm{ha}^{-1}$ de $\mathrm{N}$ adicional em março. Isto está de acordo com a recomendação feita por Werner (1971) de que a metade da adubação nitrogenada deve ser aplicada em março, quando o objetivo é aumentar o acúmulo de forragem para ser utilizada no período crítico.

Além das variações nas taxas de acúmulo da forrageira, foram observadas alterações nas características morfológicas do dossel. Independentemente do nível da adubação nitrogenada, os pastos apresentaram maiores $(\mathrm{p}<0,05)$ porcentagens de LF e menores $(\mathrm{p}<0,02)$ de Co e MM no período das águas, em comparação ao período seco (Tabela 2). O mesmo padrão de variação foi observado no resíduo pós-pastejo (Tabela 3).

Em qualquer dos níveis de adubação nitrogenada, observa-se que além da redução de MST e MSV, do pré para o pós-pastejo, houve decréscimo na porcentagem de LFe, conseqüentemente, acréscimos nas porcentagens de Co e MM, quando a forragem no pré-pastejo foi comparada ao resíduo pós-pastejo (Tabelas 2 e 3), o que indica a preferência do animal por folhas.

Analisando-se as características do resíduo de forragem pós-pastejo, não foi observado efeito de tratamento

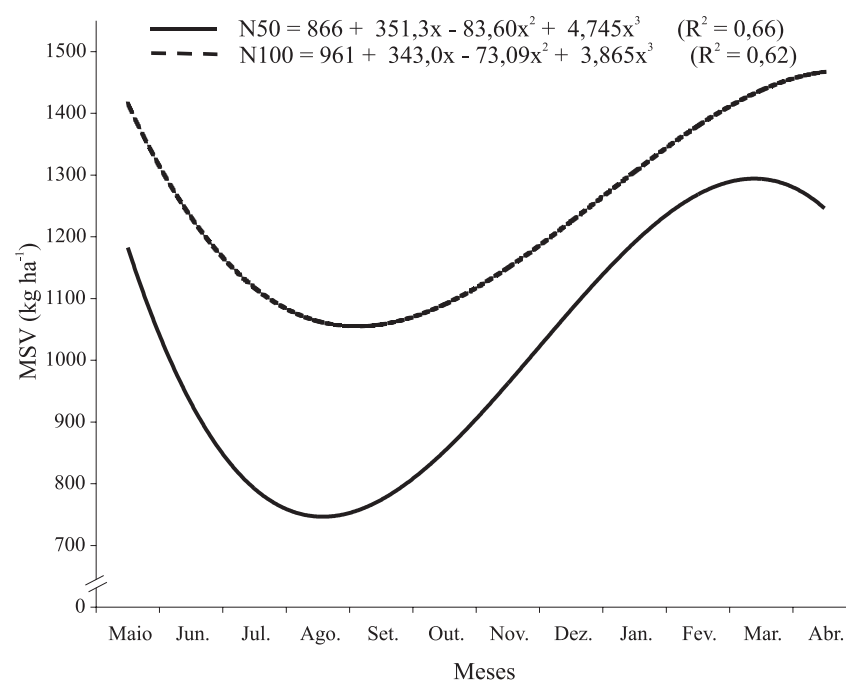

Figura 3. Variação de matéria seca verde (MSV) dos resíduos pós-pastejo, de pastos de Panicum maximum cultivar Tanzânia, com duas doses de N (N50 e N100), de acordo com os meses do ano. 
$(p=0,16)$, período do ano $(p=0,54)$, ano experimental $(p=0,10)$ e suas interações $(p>0,06)$, para a massa de MST, que foi em média 2,7 $\pm 0,17 \mathrm{tha}^{-1}$. Isto indica que o ajuste semanal das taxas de lotação foi adequado para manter os mesmos resíduos de forragem entre tratamentos, ao longo do ano e entre anos.

Entretanto, o resíduo pós-pastejo do pasto adubado com $100 \mathrm{~kg} \mathrm{ha}^{-1}$ de $\mathrm{N}$ apresentou maior ( $\mathrm{p}>0,03$ ) MSV, quando comparado ao adubado com $50 \mathrm{~kg} \mathrm{ha}^{-1}$ de $\mathrm{N}$, tendo apresentado médias de 1.200 e $1.125 \pm 20 \mathrm{~kg} \mathrm{ha}^{-1}$, respectivamente. Foram observadas, também, interações $(\mathrm{p}<0,03)$ que envolviam os efeitos de período do ano e ano experimental, quanto à MSV residual e aos componentes morfológicos (Tabela 3). Ao longo do período experimental, foi possível a manutenção de resíduos semelhantes durante o período das águas, em termos de MSV e dos componentes morfológicos. No entanto, houve variação entre anos, para a massa de MSV e estrutura do resíduo pós-pastejo durante o período seco. Isto se deve ao acúmulo de material morto no pasto, além de estar associado à senescência natural da planta que é acelerada pelo deficit hídrico. O resíduo com maior massa de MSV e maior porcentagem de LF foi observado durante o último ano experimental (1998/1999), em consequiência do menor deficit hídrico registrado durante esse período (Figura 1). As variações na massa de MSV e na composição morfológica dos resíduos, nos outros anos experimentais, refletem os maiores deficits hídricos observados nesses períodos.

Para ambos os tratamentos, a curva que melhor descreveu os resíduos de MSV foi a cúbica ( $\mathrm{p}<0,01)$. Foram observadas diferenças $(\mathrm{p}<0,05)$ entre níveis de adubação, embora não tenha havido interação $(\mathrm{p}>0,22)$ entre os efeitos de adubação e ano experimental.Assim, as quantidades de MSV, presentes nos resíduos pós-pastejo, foram apresentadas em função dos meses (Figura 3).

Durante o outono e parte do inverno, a massa de MSV do resíduo do pasto adubado com $50 \mathrm{~kg} \mathrm{ha}^{-1}$ de $\mathrm{N}$ adicional, em março, foi maior do que aquela do pasto que não recebeu adubação nitrogenada nessa ocasião (Figura 3). Euclides (2000) observou uma relação assintótica entre a disponibilidade de MSV e a produção animal. No caso de cultivares de P. maximum, o ganho de peso pelos animais foi limitado, quando a MSV do pasto era inferior a $900 \mathrm{~kg} \mathrm{ha}^{-1}$. É importante ressaltar que o pasto que não recebeu adubação nitrogenada em março, apresentou valores inferiores aos deste mês no resíduo

Tabela 3. Médias dos quadrados mínimos para a massa de matéria seca verde (MSV), porcentagens de lâminas foliares (LF) e de colmos (Co), no pós-pastejo, dos pastos de Panicum maximum cultivar Tanzânia, de acordo com o ano e o período do ano.

\begin{tabular}{|c|c|c|c|c|c|}
\hline Período do ano & $1995 / 1996$ & $1996 / 1997$ & $1997 / 1998$ & 1998/1999 & Média \\
\hline \multirow[b]{2}{*}{ Águas } & & & $\mathrm{V}\left(\mathrm{kg} \mathrm{ha}^{-1}\right)$ & & \\
\hline & $\begin{array}{c}1.380 \mathrm{Aa} \\
(49)\end{array}$ & $\begin{array}{c}1.450 \mathrm{Aa} \\
(45)\end{array}$ & $\begin{array}{c}1.360 \mathrm{Aa} \\
(35)\end{array}$ & $\begin{array}{c}1.430 \mathrm{Aa} \\
(49)\end{array}$ & $\begin{array}{c}1.405 \\
(27)\end{array}$ \\
\hline \multirow[t]{2}{*}{ Seca } & $990 \mathrm{Bab}$ & $630 \mathrm{Bb}$ & $860 \mathrm{Bb}$ & $1.190 \mathrm{Aa}$ & 917 \\
\hline & $(40)$ & (33) & (49) & $(44)$ & (26) \\
\hline \multirow[t]{2}{*}{ Média } & 1185 & 1040 & 1110 & 1310 & \\
\hline & (36) & (30) & $(26)$ & (33) & \\
\hline & & & $\mathrm{LF}(\%)$ & & \\
\hline \multirow[t]{2}{*}{ Águas } & $31,5 \mathrm{Aa}$ & $28,8 \mathrm{Ab}$ & $28,7 \mathrm{Ab}$ & $30,0 \mathrm{Ab}$ & 29,6 \\
\hline & $(0,18)$ & $(0,12)$ & $(0,14)$ & $(0,18)$ & $(0,49)$ \\
\hline \multirow[t]{2}{*}{ Seca } & $14,4 \mathrm{Bc}$ & $9,1 \mathrm{Bd}$ & $19,0 \mathrm{Bb}$ & $25,6 \mathrm{Ba}$ & 17,0 \\
\hline & $(0,16)$ & $(0,18)$ & $(0,12)$ & $(0,16)$ & $(0,48)$ \\
\hline \multirow[t]{3}{*}{ Média } & 23,0 & 18,9 & 23,8 & 27,6 & \\
\hline & $(0,36)$ & $(0,33)$ & $(0,28)$ & $(0,36)$ & \\
\hline & & & Co (\%) & & \\
\hline \multirow[t]{2}{*}{ Águas } & & $24,3 \mathrm{Aa}$ & $22,3 \mathrm{Aa}$ & $21,7 \mathrm{Aa}$ & 22,5 \\
\hline & $(1,15)$ & $(0,81)$ & $(0,94)$ & $(1,15)$ & $(0,34)$ \\
\hline \multirow[t]{2}{*}{ Seca } & 21,9Aa & $12,9 \mathrm{Bb}$ & $14,6 \mathrm{Bb}$ & 18,9Aab & 17,1 \\
\hline & $(1,05)$ & $(1,15)$ & $(0,78)$ & $(1,04)$ & $(0,33)$ \\
\hline \multirow[t]{2}{*}{ Média } & 21,9 & 18,6 & 18,5 & 20,3 & \\
\hline & $(0,31)$ & $(0,28)$ & $(0,24)$ & $(0,31)$ & \\
\hline
\end{tabular}

(1)Médias seguidas de letras iguais, maiúsculas nas colunas e minúsculas nas linhas, não diferem entre si pelo teste de Tukey, a 5\% de probabilidade; valores entre parênteses se referem ao erro-padrão da média. 
pós-pastejo de junho a outubro (Figura 3). No entanto, o pasto adubado em março apresentou valores de MSV sempre superiores a $900 \mathrm{~kg} \mathrm{ha}^{-1}$, o que indica que a quantidade de MSV é o melhor critério para o ajuste da taxa de lotação, para que a disponibilidade de forragem não seja limitante à produção animal.

Não houve efeito da adubação nitrogenada $(p>0,14)$ quanto aos teores de: proteína bruta (PB), digestibilidade in vitro da matéria orgânica (DIVMO), fibra em detergente neutro (FDN) e lignina em detergente ácido (LDA), das amostras que simularam o pastejo animal, no pré-pastejo e no resíduo pós-pastejo. Também, não foram observadas interações $(p>0,27)$ entre os efeitos de tratamento, período do ano e ano experimental. Entretanto, houve diferenças para período do ano $(\mathrm{p}<0,01)$, para ano experimental $(\mathrm{p}<0,05)$ e interação $(\mathrm{p}<0,05)$ entre estes fatores, no pré e no pós-pastejo (Tabela 3).

Os teores de PB e de DIVMO encontrados foram semelhantes aos observados por Gerdes et al. (2000), Soares et al. (2001) e Balsalobre et al. (2003), para o capim-tanzânia sob diferentes manejos. $O$ alto conteúdo de FDN, observado ao longo do ano, é uma característica de forrageiras tropicais (Euclides, 2000) e foi semelhante ao encontrado por Gerdes et al. (2000), porém superior ao encontrado por Balsalobre et al. (2003), para o capimtanzânia com 35 e 33 dias de rebrota, respectivamente. O conteúdo de lignina em detergente ácido (LDA) foi próximo ao observado por Balsalobre et al. (2003). Isto indica que a variação no valor nutritivo do capim-tanzânia, ao longo do tempo, esteve dentro do padrão encontrado em outros trabalhos com a mesma gramínea. E, quando comparado a outras gramíneas tropicais (Euclides \& Medeiros, 2003), o capim-tanzânia pode ser considerado de alto valor nutritivo.

A progressiva desfolha do dossel, com o decorrer do período de pastejo (Tabelas 1,2 e 3), teve reflexo negativo no valor nutritivo dos pastos. Houve decréscimos $(\mathrm{p}<0,01)$ nos teores de PB e DIVMO, e acréscimos $(\mathrm{p}<0,01)$ nos conteúdos de FDN e LDA (Tabela 4), no resíduo póspastejo; isto confirma que o animal seleciona a parte mais nutritiva do pasto, as lâminas foliares.

Como a quantidade de $\mathrm{N}$ adicional aplicada, $50 \mathrm{~kg} \mathrm{ha}^{-1}$, foi baixa, qualquer efeito do $\mathrm{N}$ sobre o valor nutritivo da planta pode ter sido diluído, quando os dados foram agrupados por períodos de águas e de seca. Assim, as variáveis associadas ao valor nutritivo foram analisadas em função do mês. Observou-se interação $(p<0,01)$ entre os efeitos de adubação e de mês (Tabela 5). Houve acréscimos nos teores de PB da forrageira, no pré e no

Tabela 4. Médias dos quadrados mínimos para os teores de proteína bruta (PB), de digestibilidade in vitro da matéria orgânica (DIVMO), de fibra em detergente neutro (FDN) e de lignina em detergente ácido (LDA), de amostras da simulação do pastejo, no pré e no pós-pastejo, dos pastos de Panicum maximum cultivar Tanzânia, de acordo com o ano e o período do ano ${ }^{(1)}$.

\begin{tabular}{|c|c|c|c|c|c|c|c|c|}
\hline \multirow[t]{2}{*}{ Variável } & \multicolumn{4}{|c|}{ Período das águas } & \multicolumn{4}{|c|}{ Período seco } \\
\hline & 1995/1996 & 1996/1997 & $1997 / 1998$ & $1998 / 1999$ & $1995 / 1996$ & $1996 / 1997$ & $1997 / 1998$ & $1998 / 1999$ \\
\hline & \multicolumn{8}{|c|}{ Pré-pastejo } \\
\hline \multirow[t]{2}{*}{$\mathrm{PB}(\%)$} & $11,4 \mathrm{a}$ & $11,8 \mathrm{a}$ & $12,4 \mathrm{a}$ & $9,7 b$ & $7,9 b$ & $11,3 \mathrm{a}$ & $10,2 \mathrm{a}$ & $9,3 \mathrm{ab}$ \\
\hline & $(0,46)$ & $(0,35)$ & $(0,40)$ & $(0,42)$ & $(0,80)$ & $(0,49)$ & $(0,36)$ & $(0,67)$ \\
\hline \multirow[t]{2}{*}{ DIVMO (\%) } & $58,3 \mathrm{~b}$ & $64,6 a$ & $62,0 \mathrm{ba}$ & $60,4 \mathrm{ab}$ & $60,1 \mathrm{a}$ & $64,9 \mathrm{a}$ & $60,7 \mathrm{a}$ & $60,1 \mathrm{a}$ \\
\hline & $(1,61)$ & $(1,04)$ & $(0,90)$ & $(1,30)$ & $(1,61)$ & $(1,05)$ & $(0,97)$ & $(1,45)$ \\
\hline \multirow[t]{2}{*}{ FDN $(\%)$} & $77,0 \mathrm{a}$ & $72,5 b$ & $72,7 b$ & $73,0 \mathrm{~b}$ & $75,7 \mathrm{a}$ & $73,4 \mathrm{a}$ & $74,2 \mathrm{a}$ & $74,5 \mathrm{a}$ \\
\hline & $(0,38)$ & $(0,29)$ & $(0,33)$ & $(0,34)$ & $(0,67)$ & $(0,400$ & $(0,30)$ & $(0,56)$ \\
\hline \multirow[t]{3}{*}{$\operatorname{LDA}(\%)$} & $2,8 \mathrm{a}$ & $2,4 b$ & $2,6 a b$ & $2,7 \mathrm{ab}$ & $3,8 \mathrm{a}$ & $3,6 \mathrm{a}$ & $3,6 \mathrm{a}$ & $4,3 \mathrm{a}$ \\
\hline & $(0,08)$ & $(0,06)$ & $(0,07)$ & $(0,08)$ & $(0,14)$ & $(0,09)$ & $(0,06)$ & $(0,12)$ \\
\hline & \multicolumn{8}{|c|}{ Pós-pastejo } \\
\hline \multirow[t]{2}{*}{ PB $(\%)$} & $8,8 \mathrm{ab}$ & $8,5 b$ & $9,8 \mathrm{a}$ & $7,2 \mathrm{c}$ & $4,8 b$ & $6,6 b$ & $8,1 \mathrm{a}$ & $8,0 \mathrm{a}$ \\
\hline & $(0,31)$ & $(0,24)$ & $(0,27)$ & $(0,28)$ & $(0,53)$ & $(0,32)$ & $(0,24)$ & $(0,44)$ \\
\hline \multirow[t]{2}{*}{ DIVMO (\%) } & $55,1 \mathrm{a}$ & $54,3 \mathrm{ab}$ & $55,9 \mathrm{a}$ & $50,9 \mathrm{~b}$ & $46,1 \mathrm{~b}$ & $48,1 \mathrm{~b}$ & $49,8 b$ & $56,7 \mathrm{a}$ \\
\hline & $(1,15)$ & $(0,88)$ & $(1,00)$ & $(1,03)$ & $(2,00)$ & $(1,21)$ & $(0,89)$ & $(1,68)$ \\
\hline \multirow[t]{2}{*}{ FDN $(\%)$} & $79,6 a$ & $76,9 \mathrm{bc}$ & $77,8 \mathrm{ab}$ & $76,8 \mathrm{bc}$ & $78,6 a$ & $76,2 b$ & $78,1 \mathrm{ab}$ & $77,3 \mathrm{ab}$ \\
\hline & $(0,46)$ & $(0,35)$ & $(0,40)$ & $(0,41)$ & $(0,80)$ & $(0,48)$ & $(0,36)$ & $(0,67)$ \\
\hline \multirow[t]{2}{*}{$\operatorname{LDA}(\%)$} & $4,1 \mathrm{a}$ & $3,4 b$ & $3,5 b$ & $3,4 b$ & $3,8 \mathrm{a}$ & $3,7 \mathrm{a}$ & $3,8 \mathrm{a}$ & $2,9 b$ \\
\hline & $(0,13)$ & $(0,100$ & $(0,12)$ & $(0,12)$ & $(0,23)$ & $(0,14)$ & $(0,11)$ & $(0,20)$ \\
\hline
\end{tabular}

(1) Médias, na mesma linha e dentro de período do ano, seguidas de letras iguais, não diferem entre si pelo teste de Tukey, a 5\% de probabilidade; valores entre parênteses se referem ao erro-padrão da média. 
pós-pastejo, nas primeiras avaliações após a aplicação de N, em março e abril. Elevação do conteúdo de PB do capim-tanzânia, em resposta à adubação nitrogenada, também foi observada por Quadros \& Rodrigues (2006).

Geralmente, o N aplicado às plantas forrageiras eleva a concentração de proteína na matéria seca. Como as proteínas são sintetizadas a partir de carboidratos, qualquer incremento em componentes nitrogenados requer uma diminuição compensatória em componentes não-nitrogenedos. De acordo com Van Soest (1994), o aumento no conteúdo de $\mathrm{N}$ reduz, geralmente, os teores de carboidratos solúveis e, ocasionalmente, a parede celular. E, ainda segundo este autor, mudanças na digestibilidade dependem do balanço dos fatores compensatórios. Assim, o incremento na DIVMO ocorreu apenas em março, logo após a adubação nitrogenada, entretanto, não foi observada redução no conteúdo de FDN ( $>00,31)$ no mesmo período. Quadros \& Rodrigues (2006) também não encontraram redução no conteúdo de FDN, apesar do acréscimos na DIVMS, quando as doses de $\mathrm{N}$ variaram de 100 a $230 \mathrm{~kg} \mathrm{ha}^{-1}$.

Poppi et al. (1987) indicaram que, além dos fatores nutricionais, o consumo de forragem por animais em pastejo pode ser controlado por fatores não-nutricionais, aqueles relacionados ao comportamento ingestivo. Vários estudos indicam que o consumo máximo ocorre, quando os animais estão em pastagens com alta densidade de folhas acessíveis ao animal, e que colmo e material morto podem limitar o consumo, mesmo quando a disponibilidade de matéria seca é alta. Nesse contexto, as relações lâmina foliar:colmo (LF:Co) e lâmina foliar:material morto (LF:MM) assumem grande importância, pois influenciam a facilidade de seleção e preensão da forragem, pelos animais.

A adubação nitrogenada não influenciou $(\mathrm{p}>0,44)$ a relação LF:Co, no entanto, os pastos adubados com N100 apresentaram menor $(\mathrm{p}<0,05)$ relação $\mathrm{LF} / \mathrm{MM}$ do que aqueles adubados com N50, e as médias foram, respectivamente de 2,9 e $4,8 \pm 0,1$. Isto pode ser explicado pela capacidade do $\mathrm{N}$ de acelerar o metabolismo da planta (Figura 2), o que proporciona maior renovação de tecidos e antecipa suas fases fenológicas. Do mesmo modo, Duru \& Ducrocq (2000) observaram aumento na senescência de folhas de Dactilys glomerata, no pasto adubado com $120 \mathrm{~kg} \mathrm{ha}^{-1} \mathrm{de} \mathrm{N}$, quando comparado ao não adubado.

Tanto a relação LF:Co quanto a relação LF:MM foram maiores no período das águas $(\mathrm{p}<0,01)$ do que no período seco (Tabela 6). Também, houve diferenças $(\mathrm{p}<0,02)$ entre anos e interação $(p<0,05)$, entre os efeitos de período do ano e ano experimental. As variações na relação LF:MM, entre períodos do ano e ano

Tabela 5. Médias dos quadrados mínimos para os teores de proteína bruta (PB) e de digestibilidade in vitro da matéria orgânica (DIVMO), de amostras da simulação do pastejo, no pré e no pós-pastejo, dos pastos de Panicum maximum cultivar Tanzânia com duas doses de N (N50 e N100), de acordo com o mês ${ }^{(1)}$.

\begin{tabular}{|c|c|c|c|c|c|c|c|c|}
\hline \multirow[t]{3}{*}{ Mês } & \multicolumn{4}{|c|}{ PB } & \multicolumn{4}{|c|}{ DIVMO } \\
\hline & \multicolumn{2}{|c|}{ Pré-pastejo } & \multicolumn{2}{|c|}{ Pós-pastejo } & \multicolumn{2}{|c|}{ Pré-pastejo } & \multicolumn{2}{|c|}{ Pós-pastejo } \\
\hline & N50 & N100 & N50 & N100 & N50 & N100 & N50 & N100 \\
\hline \multirow[t]{2}{*}{ Maio } & $11,6 \mathrm{a}$ & $11,5 \mathrm{a}$ & $8,4 a$ & $8,5 \mathrm{a}$ & $60,6 a$ & $62,0 \mathrm{a}$ & $51,3 \mathrm{a}$ & $51,2 \mathrm{a}$ \\
\hline & $(0,6)$ & $(0,5)$ & $(0,4)$ & $(0,4)$ & $(1,4)$ & $(1,3)$ & $(1,4)$ & $(1,3)$ \\
\hline \multirow{2}{*}{ Julho } & $10,0 \mathrm{a}$ & $9,4 \mathrm{a}$ & $6,6 a$ & $6,5 \mathrm{a}$ & $60,8 \mathrm{a}$ & $60,6 a$ & $46,3 \mathrm{a}$ & $49,1 \mathrm{a}$ \\
\hline & $(0,6)$ & $(0,5)$ & $(0,4)$ & $(0,4)$ & $(1,6)$ & $(1,3)$ & $(1,3)$ & $(1,3)$ \\
\hline \multirow[t]{2}{*}{ Setembro } & $8,4 a$ & $8,8 \mathrm{a}$ & $6,5 \mathrm{a}$ & $6,4 a$ & $57,6 \mathrm{a}$ & $56,6 a$ & $49,0 \mathrm{a}$ & $46,3 \mathrm{a}$ \\
\hline & $(0,6)$ & $(0,6)$ & $(0,4)$ & $(0,5)$ & $(2,6)$ & $(1,5)$ & $(1,4)$ & $(1,5)$ \\
\hline \multirow[t]{2}{*}{ Outubro } & $13,4 \mathrm{a}$ & $12,8 \mathrm{a}$ & $9,1 \mathrm{a}$ & $8,8 \mathrm{a}$ & $68,1 \mathrm{a}$ & $68,9 \mathrm{a}$ & $58,0 \mathrm{a}$ & $58,3 \mathrm{a}$ \\
\hline & $(0,7)$ & $(0,7)$ & $(0,5)$ & $(0,5)$ & $(1,8)$ & $(1,7)$ & $(1,8)$ & $(1,7)$ \\
\hline \multirow{2}{*}{ Novembro } & $12,3 \mathrm{a}$ & $13,2 \mathrm{a}$ & $9,2 \mathrm{a}$ & $9,5 \mathrm{a}$ & $67,8 \mathrm{a}$ & $68,7 \mathrm{a}$ & $56,2 \mathrm{a}$ & $58,2 \mathrm{a}$ \\
\hline & $(0,3)$ & $(0,8)$ & $(0,7)$ & $(0,6)$ & $(2,1)$ & $(2,1)$ & $(1,9)$ & $(1,9)$ \\
\hline \multirow[t]{2}{*}{ Janeiro } & $10,0 \mathrm{a}$ & $10,5 \mathrm{a}$ & $8,5 \mathrm{a}$ & $8,8 \mathrm{a}$ & $61,6 a$ & $61,4 \mathrm{a}$ & $53,8 \mathrm{a}$ & $53,7 \mathrm{a}$ \\
\hline & $(0,7)$ & $(0,5)$ & $(0,5)$ & $(0,4)$ & $(1,7)$ & $(1,2)$ & $(1,7)$ & $(1,3)$ \\
\hline \multirow[t]{2}{*}{ Março } & $10,9 b$ & $13,1 \mathrm{a}$ & $8,1 \mathrm{~b}$ & $9,9 \mathrm{a}$ & $59,3 b$ & $63,5 \mathrm{a}$ & $53,0 \mathrm{~b}$ & $57,4 \mathrm{a}$ \\
\hline & $(0,6)$ & $(0,6)$ & $(0,5)$ & $(0,5)$ & $(1,5)$ & $(1,5)$ & $(1,5)$ & $(1,5)$ \\
\hline \multirow[t]{2}{*}{ Abril } & $9,7 \mathrm{~b}$ & $11,3 \mathrm{a}$ & $7,3 \mathrm{~b}$ & $8,4 \mathrm{a}$ & $57,9 \mathrm{a}$ & $60,3 a$ & $49,7 \mathrm{~b}$ & $53,9 \mathrm{a}$ \\
\hline & $(0,6)$ & $(0,6)$ & $(0,4)$ & $(0,5)$ & $(1,5)$ & $(1,5)$ & $(1,5)$ & $(1,5)$ \\
\hline
\end{tabular}

${ }^{(1)}$ Médias seguidas de letras iguais, na mesma linha e dentro das condições de pré e pós-pastejo, não diferem entre si pelo teste de Tukey, a 5\% de probabilidade; valores entre parênteses se referem ao erro padrão da média. 
experimental, provavelmente estiveram associadas às variações nos balanços hídricos do solo, observados entre os anos (Figura 1).

É importante ressaltar que a relação LF:Co, observada durante o período das águas, foi superior à encontrada para a mesma gramínea por Penatti (2002), Brâncio et al. (2003) e Barbosa (2004). Provavelmente, esta diferença pode ser justificada pela altura de corte das amostras de forragem, utilizada neste experimento, que foi de $15 \mathrm{~cm}$; enquanto Brâncio et al. (2003) e Barbosa (2004) utilizaram amostras de corte rente ao solo, e Penatti (2002) utilizou amostras de $5 \mathrm{~cm}$ acima do solo.

Independentemente do ano experimental, durante o período das águas a relações LF:Co e LF:MM foram favoráveis ao pastejo. Mesmo durante o período seco, apesar de grande decréscimo na relação LF:Co, a quantidade de lâmina foliar foi, em média, de $1,5 \mathrm{vez}$ a quantidade de colmo (Tabela 6). No entanto, o decréscimo na relação LF:MM foi muito maior, durante este período, o que indica que, durante o período seco, esta relação foi mais limitante para a seleção e preensão de forragem pelos animais.

Analisando-se essas relações no resíduo pós-pastejo, observa-se que as variações foram semelhantes às do pasto no pré-pastejo. Vale ressaltar que os decréscimos nessas relações pós-pastejo reforçam que mesmo em situações menos favoráveis, como durante o período seco, os animais se esforçam para selecionar as lâminas foliares.

Tabela 6. Médias dos quadrados mínimos para as relações lâmina foliar:colmo (LF:Co) e lâmina foliar:material morto (LF:MM), no pré e no pós-pastejo, dos pastos de Panicum maximum cultivar Tanzânia, de acordo com o ano e o período do ano ${ }^{(1)}$.

\begin{tabular}{|c|c|c|c|c|c|}
\hline Período do ano & $1995 / 1996$ & $1996 / 1997$ & 1997/1998 & $1998 / 1999$ & Média \\
\hline & & & Pré-pastejo & & \\
\hline & & & LF:Co & & \\
\hline \multirow[t]{2}{*}{ Águas } & $3,8 \mathrm{Aa}$ & $4,5 \mathrm{Aa}$ & $4,6 \mathrm{Aa}$ & $3,9 \mathrm{Aa}$ & 4,2 \\
\hline & $(0,26)$ & $(0,19)$ & $(0,22)$ & $(0,22)$ & $(0,34)$ \\
\hline \multirow[t]{2}{*}{ Seca } & $1,3 \mathrm{Bb}$ & $1,2 \mathrm{Bb}$ & $2,0 \mathrm{Ba}$ & 1,4Bab & 1,5 \\
\hline & $(0,24)$ & $(0,26)$ & $(0,18)$ & $(0,30)$ & $(0,38)$ \\
\hline \multirow[t]{2}{*}{ Média } & 2,4 & 2,6 & 3,1 & 2,8 & \\
\hline & $(0,04)$ & $(0,03)$ & $(0,03)$ & $(0,04)$ & \\
\hline & & & LF:MM & & \\
\hline \multirow{2}{*}{ Águas } & $3,1 \mathrm{Ab}$ & $5,3 \mathrm{Aa}$ & $5,9 \mathrm{Aa}$ & 4,6Aab & 4,7 \\
\hline & $(0,72)$ & $(0,51)$ & $(0,59)$ & $(0,53)$ & $(0,20)$ \\
\hline \multirow[t]{2}{*}{ Seca } & $0,7 \mathrm{Ba}$ & $0,5 \mathrm{Ba}$ & $0,9 \mathrm{Ba}$ & $1,1 \mathrm{Ba}$ & 0,8 \\
\hline & $(0,66)$ & $(0,72)$ & $(0,49)$ & $(0,83)$ & $(0,22)$ \\
\hline \multirow[t]{4}{*}{ Média } & 1,9 & 2,9 & 3,4 & 2,8 & \\
\hline & $(0,57)$ & $(0,52)$ & $(0,44)$ & $(0,60)$ & \\
\hline & & & Pós-pastejo & & \\
\hline & & & LF:Co & & \\
\hline \multirow[t]{2}{*}{ Águas } & $1,4 \mathrm{Aa}$ & $1,2 \mathrm{Aa}$ & $1,3 \mathrm{Ba}$ & $1,4 \mathrm{Ba}$ & 1,5 \\
\hline & $(0,04)$ & $(0,03)$ & $(0,03)$ & $(0,04)$ & $(0,10)$ \\
\hline \multirow[t]{2}{*}{ Seca } & $0,7 \mathrm{Bb}$ & $0,8 \mathrm{Bb}$ & $1,3 \mathrm{Aa}$ & $1,3 \mathrm{Aa}$ & 0,9 \\
\hline & $(0,04)$ & $(0,04)$ & $(0,03)$ & $(0,03)$ & $(0,09)$ \\
\hline \multirow[t]{2}{*}{ Média } & 1,1 & 1,0 & 1,3 & 1,4 & \\
\hline & $(0,06)$ & $(0,05)$ & $(0,04)$ & $(0,06)$ & \\
\hline \multirow{3}{*}{ Águas } & & & LF:MM & & \\
\hline & $0,68 \mathrm{Aa}$ & $0,64 \mathrm{Aa}$ & 0,61Aa & $0,59 \mathrm{Aa}$ & 0,63 \\
\hline & $(0,02)$ & $(0,02)$ & $(0,02)$ & $(0,02)$ & $(0,01)$ \\
\hline \multirow[t]{2}{*}{ Seca } & $0,24 \mathrm{Bab}$ & $0,12 \mathrm{Bb}$ & $0,33 \mathrm{Ba}$ & $0,43 \mathrm{Aa}$ & 0,28 \\
\hline & $(0,02)$ & $(0,02)$ & $(0,02)$ & $(0,03)$ & $(0,02)$ \\
\hline \multirow[t]{2}{*}{ Média } & 0,46 & 0,38 & 0,47 & 0,51 & \\
\hline & $(0,02)$ & $(0,01)$ & $(0,01)$ & $(0,02)$ & \\
\hline
\end{tabular}

${ }^{(1)}$ Médias seguidas de letras iguais, maiúsculas nas colunas e de minúsculas nas linhas, não diferem entre si pelo teste de Tukey, a 5\% de probabilidade; valores entre parênteses se referem ao erro padrão da média. 


\section{Conclusões}

1. A adubação com $50 \mathrm{~kg} \mathrm{ha}^{-1}$ por ano de $\mathrm{N}$ é suficiente para manter a produção de forragem estável durante três anos; a partir do quarto ano de utilização do pasto, faz-se necessário aumentar a dose de $\mathrm{N}$ para $100 \mathrm{~kg} \mathrm{ha}^{-1}$ por ano.

2. A aplicação de $50 \mathrm{~kg} \mathrm{ha}^{-1}$ por ano de $\mathrm{N}$ adicional, em março, diminui a estacionalidade da produção forrageira, além de produzir forragem de maior valor nutritivo durante o outono.

\section{Agradecimentos}

Ao Conselho Nacional de Desenvolvimento Científico e Tecnológico, pelas bolsas de pesquisa concedidas.

\section{Referências}

BALSALOBRE, M.A.A.; CORSI, M.; SANTOS, P.M.; CÁRDENAS, R.R. Composição química e fracionamento do nitrogênio e dos carboidratos do capim-tanzânia irrigado sob três níveis de resíduo póspastejo. Revista Brasileira de Zootecnia, v.32, p.519-528, 2003.

BARBOSA, R.A. Características morfofisiológicas e acúmulo de forragem em capim tanzânia (Panicum maximum Jacq. cv. Tanzânia) submetido a frequiências e intensidades de pastejo. 2004. 122p. Tese (Doutorado) - Universidade Federal de Viçosa, Viçosa. Disponível em: <http://www.forragicultura.com.br/arquivos/ RodrigoAmorimBarbosaTeseUFVDZO.pdf>. Acesso em: 28 maio 2007.

BARBOSA, R.A.; NASCIMENTO JUNIOR, D.; EUCLIDES, V.P.B.; SILVA, S.C. da; ZIMMER, A.H.; TORRES JUNIOR, R.A.A. Capimtanzânia submetido a combinações entre intensidade e freqüência de pastejo. Pesquisa Agropecuária Brasileira, v.42, p.329-340, 2007.

BRÂNCIO, P.A.; EUCLIDES, V.P.B.; NASCIMENTO JUNIOR, D.; FONSECA, D.M. da; ALMEIDA, R.G. de; MACEDO, M.C.M.; BARBOSA, R.A. Avaliação de três cultivares de Panicum maximum Jacq. sob pastejo: disponibilidade de forragem, altura do resíduo póspastejo e participação de folhas, colmos e material morto. Revista Brasileira de Zootecnia, v.32, p.55-63, 2003.

CADISH, G.; SCHUNKE, R.M.; GILLER, K.E. Nitrogen cycling in a pure grass pasture and grass-legume mixture on a Red Latosol in Brasil. Tropical Grassland, v.28, p.43-52, 1994.

DURU, M.; DUCROCQ, H. Growth and senescence of the successive leaves on a cocksfoot tiller. Effect of nitrogen and cutting regime. Annals of Botany, v.85, p.645-653, 2000.

EMBRAPA. Centro Nacional de Pesquisa de Solos. Sistema brasileiro de classificação de solos. Brasília: Embrapa-SPI; Rio de Janeiro: Embrapa-CNPS, 1999. 412p.

EUCLIDES, V.P.B. Alternativas para intensificação da produção de carne bovina em pastagem. Campo Grande: Embrapa Gado de Corte, 2000, 66p.
EUCLIDES, V.P.B.; MEDEIROS, S.R. de. Valor nutritivo das principais gramíneas cultivadas no Brasil: Embrapa Gado de Corte, 2003. 43p. (Embrapa Gado de Corte. Documentos, 139).

GERDES, L.; WERNER, J.C.; COLOZZA, M.T.; POSSENTI, R.A.; SCHAMMASS, E.A. Avaliação de características de valor nutritivo das gramíneas forrageiras Marandu, Setária e Tanzânia nas estações do ano. Revista Brasileira de Zootecnia, v.29, p.955-963, 2000.

MACEDO, M.C.M. Pastagens no ecossistema Cerrados. In: SIMPÓSIO SOBRE PASTAGENS NOS ECOSSISTEMAS BRASILEIROS: pesquisas para o desenvolvimento sustentável, 1995, Brasília. Anais. Brasília: SBZ, 1995. p.28-62.

MACEDO, M.C.M. Sustainability of pasture production in the savannas of tropical America. In: INTERNATIONAL GRASSLAND CONGRESS, 18., 1997, Winnipeg, Proceedings. Winnipeg: Canadian Grassland Association. 1997. v.4. p.7-16.

MARTEN, G.C.; SHENK, J.S.; BARTON II, F.E. Near infrared reflectance spectroscopy (NIRS), analysis quality. Washington: USDA, 1985. 110p. (Agriculture Handbook, 643).

MARTHA JÚNIOR, G.B.; VILELA, L.; BARIONI, L.G.; SOUSA, D.M.G. de; BARCELLOS, A. de O. Manejo da adubação nitrogenada em pastagens. In: SIMPÓSIO SOBRE MANEJO DA PASTAGEM, 21., 2004, Piracicaba. Anais. Piracicaba: Fealq, 2004. p.155-215.

PENATI, M.A. Estudo do desempenho animal e produção do capim Tanzânia (Panicum maximum, Jacq.) em um sistema rotacionado de pastejo sob irrigação em três níveis de resíduos pós-pastejo. 2002. 143p. Tese (Doutorado) Universidade de São Paulo, Piracicaba. Disponível em: http://www.teses.usp.br/teses/disponiveis/ 11/11139/tde-17072002-155504/2002. Acesso: em 28 maio 2007.

POPPI, D.P.; HUGHES, T.P.; L'HUILLIER, P.J. Intake of pasture by grazing ruminants. In: NICOL, A.M. (Ed.). Livestock feeding on pasture. Hamilton: New Zealand Society of Animal Production, 1987. p.55-64. (Occasional Publication, N. 10).

QUADROS, D.G. de; RODRIGUES, L.R.A. Valor nutritivo dos capins Tanzânia e Mombaça adubados com nitrogênio e sob lotação rotacionada. Acta Scientiarum. Zootechny, v.28, p.385-392, 2006.

SAS INSTITUTE. SAS/STAT user software: changes and enhancements thorough release. Version 6.11. Cary: SAS Institute, 1996. SOARES, J.P.G; SALMAN, A.K.D.; BERCHIELLI, T.T.; AROEIRA, L.J.M.; VERNEQUE, R. da S. Predição do consumo voluntário do capim-tanzânia (Panicum maximum, J. cv. Tanzânia), sob pastejo, por vacas em lactação, a partir das características de degradação. Revista Brasileira de Zootecnia, v.30, p.2176-2182, 2001.

VAN SOEST, P.J. Nutritional ecology of the ruminant. 2.ed. Corvalis: O \& B Books, 1994. 374p.

WERNER, J.C. Estudo de épocas de adubação nitrogenada em capim colonião (Panicum maximum Jacq.) para aumento de produção de forragem nas secas. Boletim de Indústria Animal, v.27/28, p.361368, 1971.

WERNER, J.C.; PAULINO, V.T.; CANTARELLA, H. Forrageiras. In: RAIJ, B. van; CANTARELLA, H.; QUAGGIO, J.A.; FURLANI, A.M.C. (Ed.). Recomendações de adubação e calagem para o estado de São Paulo. 2ed. Campinas: IAC, 1996. p.261-273. (IAC. Boletim Técnico, 100). 